GUÍAS DE PRÁCTICAS

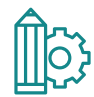

GUÍA DE PROCEDIMIENTOS PARA EL ÁREA DE IMAGENOLOGÍA DIAGNÓSTICA DE LA CLÍNICA VETERINARIA ANIMALES DE COMPAÑÍA UNIVERSIDAD COOPERATIVA DE COLOMBIA

Javier Hernando Albarracín-Navas Universidad Cooperativa de Colombia,

Bucaramanga, Colombia
Documentos de docencia | Course Work coursework.ucc.edu.co N. ${ }^{\circ} 4$, octubre de 2016 doi: http://dx.doi.org/10.16925/greylit.1606 


\section{ACERCA DEL AUTOR}

Javier Hernando Albarracín-Navas, Médico Veterinario Zootecnista, Especialista en Docencia Universitaria. Profesor asociado, Medicina Veterinaria y Zootecnia, Universidad Cooperativa de Colombia, Bucaramanga, Colombia.

Correo electrónico: javier.albarracin@campusucc.edu.co

\section{CómO CITAR ESTE DOCUMENTO}

Albarracín-Navas JH (2016). Guía de procedimientos para el área de imagenología diagnóstica de la clínica veterinaria Animales de Compañía. (Documento de docencia N. ${ }^{\circ}$ 4). Bogotá: Ediciones Universidad Cooperativa de Colombia. doi: http://dx.doi.org/10.16925/greylit.1606

Este documento puede ser consultado, descargado o reproducido desde nuestro repositorio de documentos de trabajo (http:// coursework.ucc.edu.co) para uso de sus contenidos, bajo la licencia de Creative Commons Reconocimiento-No Comercial-Sin Obra Derivada 4.0 Internacional. http://creativecommons.org/ licenses/by-nc-nd/4.0/ 


\section{TABLA DE CONTENIDO}

REgLAmento 5

Factores que influyen en los efectos biológicos 5

Clasificación de los efectos biológicos 5

Protección radiológica 6

$\begin{array}{ll}\text { Niveles orientativos de dosis } & 7\end{array}$

INTRODUCCIÓN

$\begin{array}{ll}\text { PROPÓSITO DE LA PRÁCTICA } & 8\end{array}$

RECOMENDACIONES PRÁCTICAS SOBRE LA GUÍA 8

MARCO TEÓRICO 8

¿Qué método emplear como medio diagnóstico por imagen? 8

Principios generales para la interpretación de las imágenes 9

EQUIPO DE RADIOGRAFÍA IO

$\begin{array}{ll}\text { Principios físicos } & 10\end{array}$

$\begin{array}{ll}\text { Medios de contraste } & 11\end{array}$

$\begin{array}{ll}\text { Proyecciones y posiciones radiológicas } & 11\end{array}$

EQUIPO DE ECOGRAFÍA

$\begin{array}{ll}\text { Principios físicos } & 16\end{array}$

Formación de la imagen ecográfica 16

$\begin{array}{ll}\text { Ecogenicidad de los tejidos } & 17\end{array}$

$\begin{array}{ll}\text { Artefactos } & 17\end{array}$

El ecógrafo y sus componentes $\quad 19$

Planos ecográficos 20

Modos en ecografía $\quad 20$

Protocolo de realización de ecografías $\quad 21$

EQUIPO DE ENDOSCOPIA 2 I

Composición de un endoscopio $\quad 22$

Tipos de endoscopios $\quad 22$

Limpieza y desinfección $\quad 22$

Protocolo de realización de endoscopias $\quad 22$

OBjetivos 23

Objetivo general 23

Objetivos específicos 23

MATERIAles $\quad 23$

$\begin{array}{lr}\text { REFERENCIAS } & 25\end{array}$ 


\title{
04 GUÍA DE PROCEDIMIENTOS PARA EL ÁREA DE IMAGENOLOGÍA DIAGNÓSTICA DE LA CLÍNICA VETERINARIA ANIMALES DE COMPAÑÍA UNIVERSIDAD COOPERATIVA DE COLOMBIA
}

\author{
Javier Hernando Albarracín-Navas
}

\section{RESUMEN}

El uso y la interpretación de imágenes diagnósticas en el manejo clínico diario juegan un papel muy importante al momento de enfrentar patologías que necesiten de tal herramienta. Esta guía tiene como objetivo informar al cuerpo médico y estudiantil el paso a paso del uso de cada uno de los equipos que consta esta área, así como describe las diferentes técnicas y normas de bioseguridad requeridas para cada uno de ellos. Esta guía describe los pasos para la toma de placas radiológicas, las normas de radioprotección, el manejo del paciente, la realización de diferentes técnicas radiológicas y las diferentes posiciones que se deben tener en cuenta para una buena toma de una radiografía. Estos mismos procesos serán realizados para el manejo del paciente que necesite del diagnóstico por medio ecográfico o endoscópico donde se mencionaran las diferentes técnicas y puntos a tener en cuenta para la correcta ejecución e interpretación de estas imágenes, brindándole así al estudiante y al personal de la clínica una guía que le permita en un futuro más facilidad para el manejo e interpretación de las imágenes generadas por los diferentes equipos que se manejan en esta área.

Palabras clave: radiología, endoscopia, ecografía, radioprotección. 


\section{REGLAMENTO}

La Comisión Internacional de Protección Radiológica (ICRP) fundada en 1928 surge con el fin de establecer una filosofía de la protección radiológica fundamentada en los conocimientos científicos sobre los efectos biológicos de las radiaciones ionizantes (Preciado y Luna, 2010).

Actualmente, estas normas son de uso indispensable y constituyen el origen de la disciplina denominada "Protección radiológica".

Basados en las normatividad colombiana de bioseguridad, Ley 657 de 2001, decreto 3039 del 2007 y Ley 9 de 1979, todos los usuarios de los equipos radiológicos o expuestos a los rayos $\mathrm{X}$ deben hacer uso y disponer de normas que garanticen la protección y la disminución de los riesgos a los que se exponen durante su labor, asegurando un nivel adecuado de protección al ser humano.

Los efectos que causa la radiación pueden ser agudos, que aparecen poco tiempo después de la exposición o crónicos por que aparecen muchos años después de la exposición y se ven reflejados a nivel celular.

Factores que influyen en los efectos biológicos

Los efectos biológicos de la radiación se derivan del daño que esta puede causar a nivel celular, en la molécula del ADN.
Estos factores se dividen en físicos, fisiológicos y ambientales.

- Físicos: este factor depende de las características de la radiación, como lo son la dosis, el tiempo de exposición y el tamaño del área expuesta.

- Fisiológicos: depende de las características de la persona que ha sido expuesta (edad, sexo, metabolismo, etc.).

- Ambientales: este factor depende de la presión del oxígeno y del estado del ciclo celular.

La radiación puede ocasionar daño al ADN de dos formas. Directa cuando se deposita energía en esta molécula o indirectamente por medio de los radicales libres.

\section{Clasificación de los efectos biológicos}

Los efectos biológicos causados por la exposición a los rayos x se clasifican en somáticos, deterministas y estocásticos.

- Efectos somáticos: son los que se presentan en el personal irradiado y pueden ser deterministas o estocásticos.

- Efectos deterministas: estos efectos aparecen a partir de un cierto umbral de exposición y se presentan con una determinada dosis de radiación (tabla 1). 
TABLA 1. Efectos deterministas a nivel celular

\begin{tabular}{|c|c|c|c|c|c|}
\hline Tejido & Efecto & $\begin{array}{l}\text { Periodo de } \\
\text { latencia } \\
\text { aproximado }\end{array}$ & $\begin{array}{c}\text { Umbral } \\
\text { aproximado } \\
\left(\begin{array}{c}\text { Gy) } \\
\text { a }\end{array}\right.\end{array}$ & $\begin{array}{l}\text { Dosis } \\
\text { efectos } \\
\text { severos }\end{array}$ & Causa \\
\hline $\begin{array}{l}\text { Sistema } \\
\text { hematopoyético }\end{array}$ & $\begin{array}{l}\text { Infecciones } \\
\text { Hemorragias }\end{array}$ & 2 semanas & 0,5 & 2,0 & $\begin{array}{l}\text { Leucopenia } \\
\text { Plaquetopenia }\end{array}$ \\
\hline Sistema Inmune & $\begin{array}{l}\text { Inmunosupresión } \\
\text { Infección sistémica }\end{array}$ & Algunas horas & 0,1 & 1,0 & Linfopenia \\
\hline $\begin{array}{l}\text { Sistema } \\
\text { gastrointestinal }\end{array}$ & $\begin{array}{l}\text { Deshidratación } \\
\text { Desnutrición }\end{array}$ & 1 semana & 2,0 & 5,0 & $\begin{array}{l}\text { Lesión del epitelio } \\
\text { intestinal }\end{array}$ \\
\hline Piel & Escamación & 3 semanas & 3,0 & 10,0 & Daño en la capa \\
\hline Testiculo & Esterilidad & 2 meses & 0,2 & 3,0 & Aspermia celular \\
\hline Ovario & Esterilidad & $<1$ mes & 0,5 & 3,0 & $\begin{array}{l}\text { Muerte interfásica } \\
\text { del oocito }\end{array}$ \\
\hline Pulmón & Neumonia & 3 meses & 8,0 & 10,0 & $\begin{array}{l}\text { Fallos en la barrera } \\
\text { alveolar }\end{array}$ \\
\hline Cristalino & Cataratas & $>1$ año & 0,2 & 5,0 & $\begin{array}{l}\text { Fallos en la } \\
\text { maduración }\end{array}$ \\
\hline Tiroides & $\begin{array}{l}\text { Deficiencias } \\
\text { metabólicas }\end{array}$ & $<1$ año & 5,0 & 10,0 & Hipotiroidismo \\
\hline $\begin{array}{l}\text { Sistema nervioso } \\
\text { central }\end{array}$ & $\begin{array}{l}\text { Encefalopatias y } \\
\text { mielopatias }\end{array}$ & $\begin{array}{l}\text { Muy variable } \\
\text { seguun dosis }\end{array}$ & 15,0 & 30,0 & $\begin{array}{l}\text { Demielinización y } \\
\text { daño vascular }\end{array}$ \\
\hline
\end{tabular}

Nota. Tomado de Efectos de la radiación sobre el organismo, por J. M. Roldán-Arjona, s. f. [Internet].

- Efectos estocásticos: Estos efecto tienen una naturaleza aleatoria y la probabilidad de que ocurran aumentan con la dosis a la que se expone. Están influidos por muchos factores y no aparecen a partir de dosis umbral. Pueden ser de naturaleza hereditaria.

\section{Protección radiológica}

El conjunto de medidas que se establecen por las organizaciones para la utilización segura de la radiación ionizante es denominado "Protección radiológica” y se emplea para garantizar al personal expuesto y a la población en general, la disminución de los posibles riesgos que se pueden ocasionar o derivar por la exposición a la radiación.

En 1977, la ICRP establece un sistema de protección radiológica que se basa en tres principios básicos: justificación, optimización y limitación de dosis para lograr el objetivo propuesto: proteger al personal y al medio ambiente (Roldán-Arjona, s. f.).

- Justificación: son todas las actividades que pueden incrementar la exposición a la radiación y que producen suficiente beneficio al personal expuesto o a la sociedad, como para compensar el daño que puede ocasionar dicha exposición.

- Optimización: las dosis individuales y el número de personas expuestas deben mantenerse tan bajas como sea posible, teniendo en cuenta las consideraciones sociales y económicas.

- Limitación de dosis: la exposición individual debe estar sujeta a los límites en la dosis recibida y en caso de exposiciones potenciales, a cierto control de riesgo. Los límites varían dependiendo del nivel de exposición (público o trabajadores profesionalmente expuestos).

Para reducir a niveles aceptables la exposición a la radiación, es necesario establecer medidas para el diseño de las instalaciones, especificar límites de dosis para los trabajadores, utilizar los equipos destinados para la protección (figura 1). 
Las tres reglas fundamentales contra toda fuente de radiación son:

- Distancia: la intensidad disminuye con el cuadro de distancia. Entre más lejos se esté de la fuente de radiación, menor será la exposición.

- Blindaje: poner barreras protectoras entre la fuente radioactiva y las personas. Se emplean chalecos plomados, protector de tiroides plomado, lentes plomados, guantes plomados

- Tiempo: disminuir la duración de la exposición a las radiaciones.
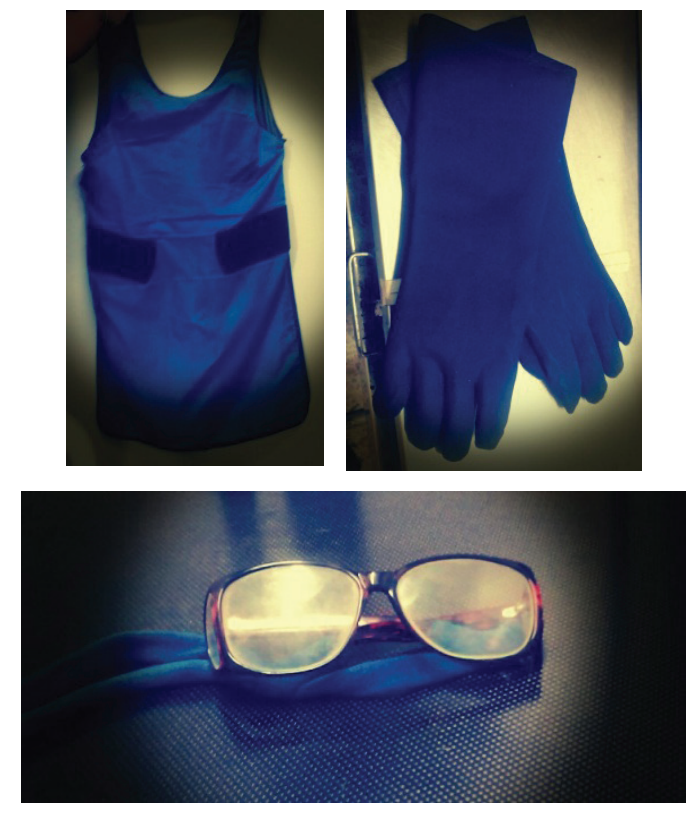

FIGURA 1. Equipo de protección radiológica (chaleco, guantes y lentes]. Elaboración propia.

\section{Niveles orientativos de dosis}

Los niveles orientativos de dosis son aquellos utilizados para los procesos de optimización en la exposición, se encaminan a disminuir a cero las dosis innecesarias obtenidas por el público y los trabajadores profesionalmente expuestos y permiten tener una referencia acerca de cuantos estudios radiológicos se pueden practicar evitando un daño mayor "dosis baja absorbida".

La dosis de radiación se mide en milisieverts (mSv) o rem. Este mide la dosis efectiva y tiene en cuenta el tipo de radiación y la parte del cuerpo que ha sido irradiada (tabla 2).

TABLA 2. Límites de dosis NoM-156-SSA1-1996

\begin{tabular}{c|c}
\hline Límite de dosis anual para el personal & $50 \mathrm{mSv}$ \\
\hline Límite para mujeres embarazadas & $15 \mathrm{mSv}$ \\
\hline Límite para el público & $5 \mathrm{mSv}$ \\
\hline
\end{tabular}

Nota. Tomado de Medidas básicas de protección radiológica, por M. Preciado y V. Luna, 2010, en Cancerología, 1.

Para medir la dosis absorbida de las radiaciones ionizantes por un determinado material, se emplea el gray (Gy) que es una unidad derivada del sistema internacional de unidades, es equivalente a la absorción de un julio (J) de energía ionizante por un kilogramo (Kg) de material irradiado.

TABLA 3. Valores de dosis umbral para efectos deterministas

\begin{tabular}{c|c}
\hline EFECTO DETERMINISTA & $\begin{array}{c}\text { UMBRAL DE DOSIS } \\
\text { EQUIVALENTE [Exposición } \\
\text { única) (Gy) }\end{array}$ \\
\hline Esterilidad permanente hombre & $3.5-6.0$ \\
\hline Esterilidad permanente mujer & $2.5-6.0$ \\
\hline Opacidad del cristalino & $0.5-2.0$ \\
\hline Cataratas & 5.0 \\
\hline Depresión hematopoyética & $3.5-6.0$ \\
\hline
\end{tabular}

Nota. Tomado de Medidas básicas de protección radiológica, por M. Preciado y V. Luna, 2010, en Cancerología, 1.

\section{INTRODUCCIÓN}

Esta guía de procedimientos para el área de imagenología diagnóstica, ha sido elaborado con el fin de garantizar un buen desempeño laboral y clínico, permitiendo a la comunidad estudiantil adquirir destrezas y conocimientos sobre los equipos encontrados en el área como son: ecógrafo, rayos x y endoscopio, sobre su importancia en el diagnóstico de 
enfermedades, funcionamiento y manejo de los mismos como de los pacientes.

\section{PROPÓSITO DE LA PRÁCTICA}

El propósito de esta práctica es que el estudiante identifique todas y cada una de las herramientas que existen como apoyo diagnostico en el área de imagenología, donde seguido a esto y conseguido este propósito, se realizara el apoyo docente en su uso y manejo, donde el alumnado será capacitado para que tome, haga e interprete cada una de las imágenes obtenidas por las diferentes técnicas que cada equipo o patología sugiere, permitiéndole correlacionar clínicamente los hallazgos y la sintomatología de un paciente el cual necesite el apoyo de este tipo de método diagnóstico.

Los resultados que se esperan obtener de esta práctica, es que el estudiante salga capacitado en el conocimiento y manejo de cada uno de los equipos que conforman el área de imagenología, el desarrollo de las diferentes técnicas requeridas para cada uno y la importancia que implica realizar un correcto análisis e interpretación de todas y cada una de las imágenes adquiridas para así poder orientar un mejor diagnostico a aquellos pacientes que ameriten estas herramientas dentro de su proceso clínico y diagnóstico.

\section{RECOMENDACIONES PRÁCTICAS SOBRE LA GUÍA}

Para el manejo de esta guía el estudiante debe tener en cuenta todas y cada una de las indicaciones o pasos a seguir, ya que estos son muy importantes para un buen desarrollo de los objetivos establecidos con cada uno de los equipos que comprenden el área de imagenología diagnóstica.

Cabe resaltar que las normas de bioseguridad establecidas para el manejo de ciertos equipos, específicamente el de radiología, el cual puede generar un fuerte impacto negativo en la salud de aquellas personas que manipulen dicho equipo están consignada en esta guía $\mathrm{y}$ debes ser seguidas con total rigurosidad y compromiso para evitar en un futuro eventos lamentables.

Esta guía fue creada con el fin de que el estudiante antes de que se enfrente al uso y manejo de cada equipo, sea informado de sus funciones y usos, y le permita de una manera más precisa, confiable y exitosa el buen desarrollo de su práctica académica en el área de imagenología.

\section{MARCO TEÓRICO}

\section{¿Qué método emplear como medio diagnóstico por imagen?}

Para obtener un buen diagnóstico por imagen, se debe elegir la técnica adecuada y acorde a las necesidades o lo que se requiere observar. Para ello, se debe determinar por medio de la inspección clínica realizada al paciente durante la consulta, la región a visualizar, la causa para pedir una prueba de diagnóstico por imagen, la urgencia, si es posible realizar sedación o anestesia y las posibilidades económicas del cliente (Gutierrez, 2004).

La radiología convencional es una prueba económica, que proporciona información detallada y rápida de las imágenes y permite llegar al diagnóstico de diversas patologías. La inspección radiológica del organismo ofrece una perspectiva panorámica inmediata en las regiones anatómicas estudiadas, excluyendo el sistema nervioso central y las partes blandas del cráneo (Liste, 2010). Aunque es una herramienta que permite llegar a un diagnostico en diversas ocasiones, se debe tener en cuenta las limitaciones que presenta ya que solamente se muestran las variaciones de tamaño, forma y densidad radiográfica de los órganos. 
dar por movimiento, magnificación y mal uso del equipo (Han y Hurd, 2000)ํ.

- Complejidad: la percepción de cualquier imagen particular está limitada por la presencia de todas las otras imágenes en el campo visual.

- Patrón de búsqueda: orden mental establecido por la persona que interpreta la imagen.

- Memoria del observador: el radiólogo confronta la imagen que percibe con la que tiene en la memoria, por lo cual es capaz de descifrar lo anormal.

- Ambiente de lectura: el radiólogo necesita concentración y evitar distracciones como ruido e interrupciones.

\section{Descripción de signos en radiología}

- Radio denso o radio-opaco: son los tejidos que absorben los rayos $\mathrm{x} y$ hace que la placa quede sin velar en este sitio, se ven de color blanco. Ejemplo: Estructuras óseas.

- Radio lúcido: son los tejidos que dejan pasar los rayos $\mathrm{x}$ fácilmente y se ennegrece la placa. Ejemplo: Aire y grasa.

Principios generales para la interpretación de las imágenes

Existen diversos factores que influyen para que las imágenes puedan ser vistas, leídas e interpretadas

\section{Percepción visual}

Para poder interpretar una imagen y detectarla como anormal, influyen varios factores:

- Borrosidad: la percepción de una imagen depende de la característica de sus bordes y no de su área. La borrosidad se puede

\section{Descripción de signos en ecografía}

- Hiperecoico o ecogénico: cuando una lesión se ve más blanca que el tejido en el que está.

- Hipoecoico: cuando se ve más oscuro.

- Anecoico: cuando es totalmente negra. Ejemplo: líquido.

- Refuerzo acústico: es cuando los tejidos profundos a una lesión se ven resaltados.

1 Han CM, Hurd CD. Diagnóstico practico por imagen para técnicos veterinarios. Editorial Acribia S.A.; 2000. 
Esto se da cuando el haz de sonido tiene un cambio brusco de velocidad, lo cual indica que la lesión tiene contenido líquido.

- Sombra acústica: el sonido es totalmente absorbido y reflejado en una lesión, no llega a los tejidos distales y da una imagen negra. Ejemplo: Cálculos, calcificaciones y estructuras óseas.

\section{EQUIPO DE RADIOGRAFÍA}

La radiología es una rama de la medicina que se encarga de generar imágenes por medio de radiación de las diferentes partes del cuerpo; es empleada para el diagnóstico de diversas enfermedades y para visualizar anormalidades anatómicas que no se pueden observar a simple vista.

En Veterinaria, es una de las herramientas diagnósticas más empleadas por su gran utilidad, ya que permite valorar con gran precisión las lesiones óseas, diagnosticar diversas patologías, lesiones pulmonares, cardiacas, de tráquea, de esófago, cálculos vesicales y uretrales, obstrucciones intestinales, cuerpos extraños.

En la Clínica Veterinaria Animales de Compañía se dispone de un equipo de rayos $\mathrm{x}$ digital que permite visualizar las imágenes en la pantalla de un computador en el cual se puede modificar los contrastes, el brillo, aumentar la imagen, realizar mediciones, entre otras, con el fin de obtener una imagen de calidad y permitir una mejor visualización.

\section{Principios físicos}

Los rayos $\mathrm{x}$ se producen por el choque de electrones emitidos por un cátodo contra los electrones y el núcleo de los elementos de un ánodo. Los pasos son:

- Emisión termoiónica: se hace pasar corriente a través de un cátodo que es un filamento de tungsteno. Esta corriente, es controlada en el equipo por los miliamperios, la cual genera calor y hace que los electrones de las últimas capas entren en emisión termoiónica.

- A mayor miliamperaje por segundo (MAS), más electrones entran en emisión, lo que implica, mayor cantidad de rayos X (Lois, 2010).

- Generación de corriente: al tubo dentro del cual está el cátodo en emisión termoiónica se le aplica una corriente eléctrica controlada en el equipo por el kilovoltaje. Los electrones que están en emisión termoiónica salen hacia el ánodo con gran cantidad de energía cinética.

- A mayor cantidad de kilovoltaje, más energía cinética se le suministra a los electrones.

- Frenado por el ánodo: el ánodo es generalmente un disco rotatorio constituido por elementos de alto número atómico. Los electrones que vienen

- del cátodo chocan con los electrones y el núcleo de los elementos del ánodo. El 99\% de la energía cinética se convierte en calor y el 1\% en energía electromagnética de alta frecuencia, los rayos $\mathrm{X}$.

- Interacción con el paciente: los rayos X generados se orientan hacia el paciente, en donde pierden energía. El paciente sufre ionización en sus átomos.

- Obtención de la imagen: los rayos x que salen del paciente son filtrados por una rejilla que solo deja pasar los que vayan en sentido perpendicular y llegan al chasis en donde hay dos elementos: las pantallas intensificadoras y las películas. 


\section{Medios de contraste}

Los medios de contraste son sustancias que se administran al paciente para poder observar órganos que no eran evidentes o no eran claras en una placa normal. Estos permiten determinar la posición, el tamaño, la forma, la arquitectura interna y la función de un órgano. Por ejemplo la velocidad del vaciado gástrico (Mendoza, s. f.).

Propiedades requeridas para un medio de contraste

- Diferente poder de absorción de los tejidos

- Sin efectos colaterales o tóxicos

- Delineación exacta de un órgano

- Persistencia durante un tiempo suficiente para tomar las radiografías

- Expulsión total del organismo

\section{Tipos de medios de contraste}

Existen dos grupos de medios de contraste que se diferencian por que absorben más o menos radiación incidente, que los tejidos circundantes.

- Negativos: son más radiolúcidos que los tejidos circundantes por lo que se observan más oscuros. Se utilizan los gases, para obtener los contrastes negativos, el más empleado es el aire. Se utilizan para neumocistografías, neumogastrogramas, neumocolón o neumoperitoneo.

- Positivos: son más radioopacos por lo que se observan más blancos. Son elementos de alto número atómico y los más empleados son el sulfato de bario y el yodo.

- Sulfato de bario: es un polvo de color blanco que se debe preparar dependiendo del espesor requerido, se utiliza principalmente para el tracto gastrointestinal. Es de baja toxicidad, da un excelente detalle de las mucosas, no es absorbido y es palatable.

- Yodo: se inyectan en el torrente sanguíneo para urogramas, cistogramas, cardioangiografía, venografía portal, entre otras. Es una sustancia hidrosoluble y versátil. Es irritante y altas dosis pueden ser tóxicas.

\section{Proyecciones y posiciones radiológicas}

Las proyecciones radiológicas describen la dirección del haz primario una vez que sale de la ventana de emisión hacia el paciente, el sitio donde penetra el rayo y el sitio por el que sale y determinan la posición del paciente.

Las posiciones radiológicas hacen referencia a la trayectoria del haz de rayos X a través de la estructura que se radiografía (Unzeta, 2009). El primer término describe la superficie de la estructura sobre la que penetra el haz primario y el segundo término describe la superficie de la estructura por la que sale el haz. Ejemplo: Si se pide una proyección ventrodorsal (VD) de abdomen, se indica que el haz de rayos penetrará el abdomen ventralmente y lo abandonará dorsalmente.

El termino posición (derecha o izquierda) empleado en una proyección latero lateral (LL) hace referencia al decúbito del paciente y no a la proyección. Ejemplo: Se pide una proyección latero lateral posición derecha se indica que es el lado derecho del paciente el que se debe apoyar en la mesa (Han, Hurd y Kurklis, 1997).

\section{Cabeza}

\section{Proyección latero lateral (LL)}

- Colocar el paciente en decúbito lateral, con el lado afectado sobre la mesa 
- Ubicar la cabeza del paciente sobre el chasis

- Situar dorsalmente los pabellones auriculares para que no interfieran con la imagen radiológica

- Situar el haz de rayos x por debajo del ojo.

Para observar un ejemplo de proyección, véase figura 2.

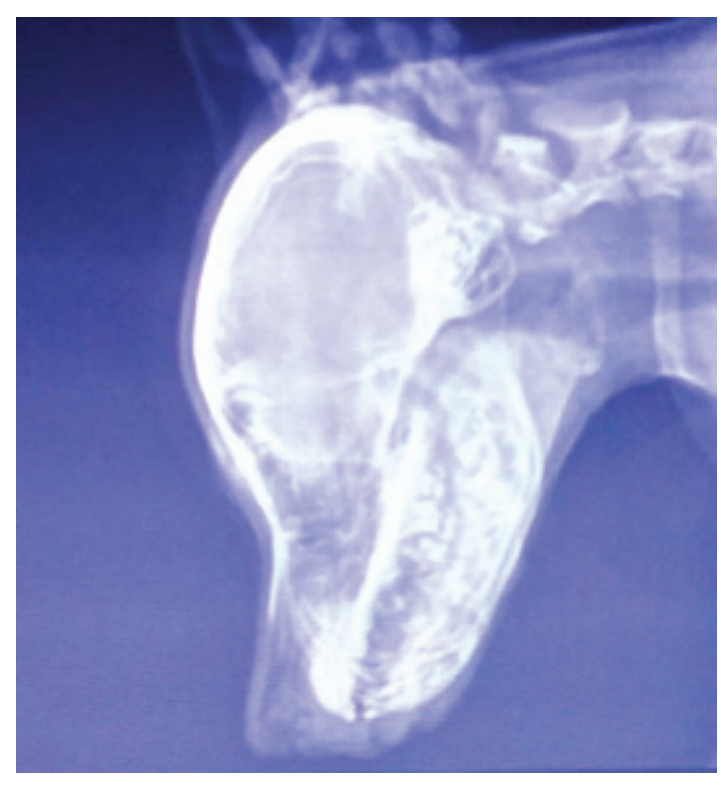

FIGURA 2. Proyección latero lateral de cabeza. Elaboración propia.

\section{Proyección rostro caudal (RC)}

- Colocar al paciente en decúbito dorsal

- Ubicar la cabeza del paciente sobre el chasis

- Estirar las extremidades anteriores hacia caudal

- Orientar el hocico del paciente en vertical, mirando hacia el tubo de rayos $\mathrm{x}$

- Tomar la radiografía
Proyección rostro caudal con la boca abierta

- Colocar al paciente en decúbito dorsal, con la cabeza sobre el chasis.

- Estirar las extremidades anteriores caudalmente

- Orientar el hocico del paciente en vertical, mirando hacia el tubo de rayos $\mathrm{x}$, de tal forma que el paladar duro quede perpendicular al haz de rayos primario y se mantiene en esta posición con la ayuda de una venda.

- Con la ayuda de otra venda atada a la mandíbula, abrir la boca del paciente.

- Situar los pabellones auriculares lateralmente

- Centrar el haz de rayos x sobre la base de la lengua o sobre el paladar blando.

- Tomar la radiografía

Tórax

\section{Proyección Dorsoventral (DV)}

- Colocar al paciente en decúbito esternal sobre la mesa.

- Mantener la cabeza del paciente apoyada sobre la mesa en posición natural.

- Estirar las extremidades anteriores cranealmente y las posteriores caudalmente.

- Ubicar el haz de rayos x sobre el tórax a nivel de la silueta cardiaca.

- Tomar la radiografía en pico de máxima inspiración, esto aumenta el contraste pulmonar. 


\section{Proyección Ventrodorsal (VD)}

- Colocar al paciente en decúbito dorsal.

- Mantener la cabeza en posición natural.

- Estirar las extremidades anteriores cranealmente y las posteriores caudalmente.

- Ubicar el haz de rayos x sobre el tórax a nivel del cartílago xifoides.

- Realizar la radiografía en pico de máxima inspiración.

\section{Proyección latero lateral (LL)}

- Ubicar al paciente lateralmente dependiendo de la posición requerida derecha o izquierda.

- Mantener la cabeza en extensión normal.

- Estirar las extremidades anteriores hacia craneal.

- Centrar el haz de rayos x sobre el tórax a nivel de la silueta cardiaca.

- Tomar la radiografía en el pico de máxima inspiración.

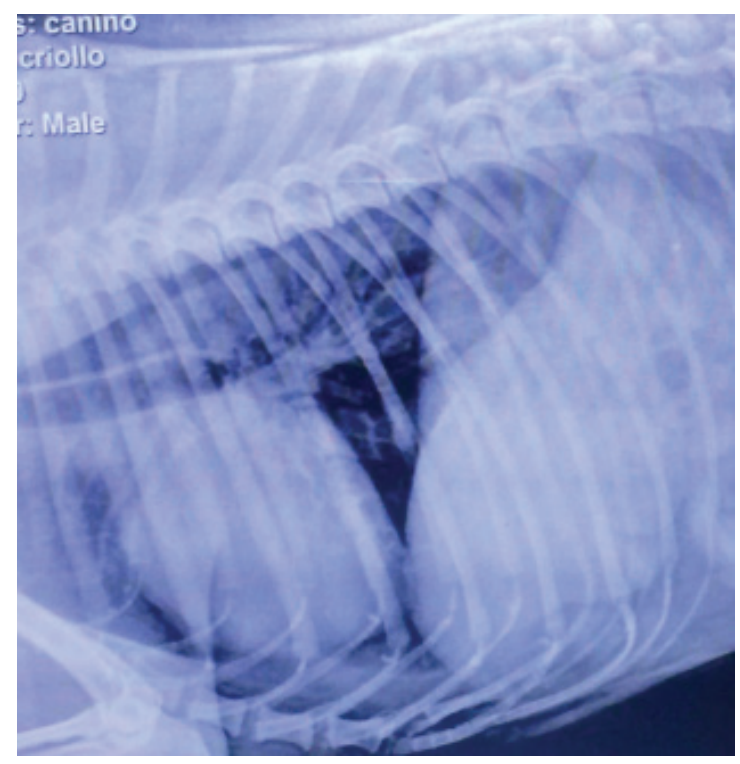

FIGURA 3. Proyección latero lateral de tórax. Elaboración propia.

\section{Abdomen}

\section{Proyección Dorsoventral (DV)}

- Colocar al paciente en decúbito esternal sobre la mesa.

- Mantener la cabeza del paciente apoyada sobre la mesa en posición natural.

- Estirar las extremidades anteriores cranealmente y las posteriores caudalmente.

- Ubicar el haz de rayos x sobre el abdomen.

- Tomar la radiografía.

\section{Proyección Ventrodorsal (vD)}

- Colocar al paciente en decúbito dorsal.

- Mantener la cabeza en posición natural.

- Estirar las extremidades anteriores cranealmente y las posteriores caudalmente.

- Ubicar el haz de rayos x sobre el abdomen.

- Realizar la radiografía.

\section{Proyección latero lateral (LL)}

- Ubicar al paciente lateralmente dependiendo de la posición requerida derecha o izquierda.

- Mantener la cabeza en extensión normal.

- Estirar las extremidades anteriores hacia craneal.

- Centrar el haz de rayos x sobre el abdomen.

- Tomar la radiografía. 


\section{Cadera}

\section{Proyección Dorsoventral (DV)}

- Colocar al paciente en decúbito esternal sobre la mesa.

- Ubicar la cadera sobre el chasis.

- Estirar las extremidades anteriores cranealmente y las posteriores caudalmente.

- Ubicar el haz de rayos x sobre la cadera.

- Tomar la radiografía.

\section{Proyección Ventrodorsal (VD)}

- Colocar al paciente en decúbito dorsal.

- Ubicar la cadera sobre el chasis.

- Estirar las extremidades anteriores cranealmente y las posteriores caudalmente.

- Ubicar el haz de rayos x sobre la cadera.

- Realizar la radiografía.

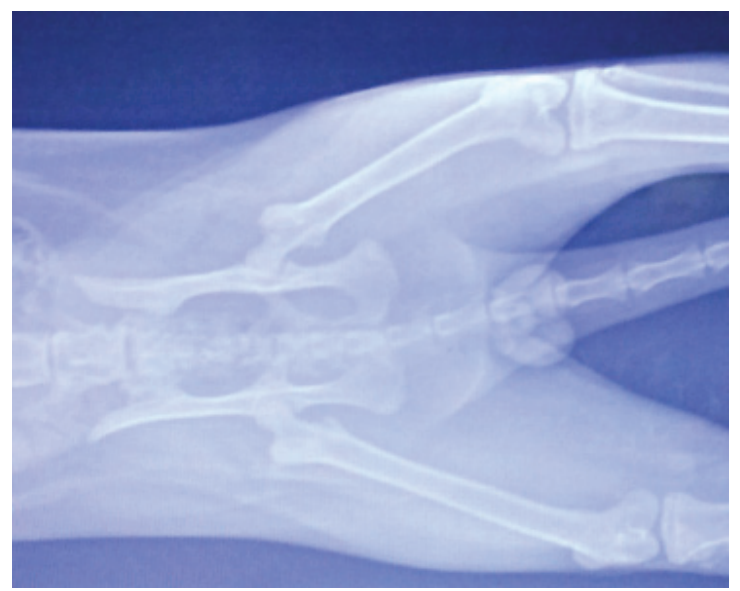

FIGURA 4. Proyección ventrodorsal de cadera. Elaboración propia.

\section{Proyección latero lateral (LL)}

- Ubicar al paciente en decúbito lateral.

- Estirar las extremidades anteriores hacia craneal.
- Centrar el haz de rayos x sobre la cadera.

- Tomar la radiografía.

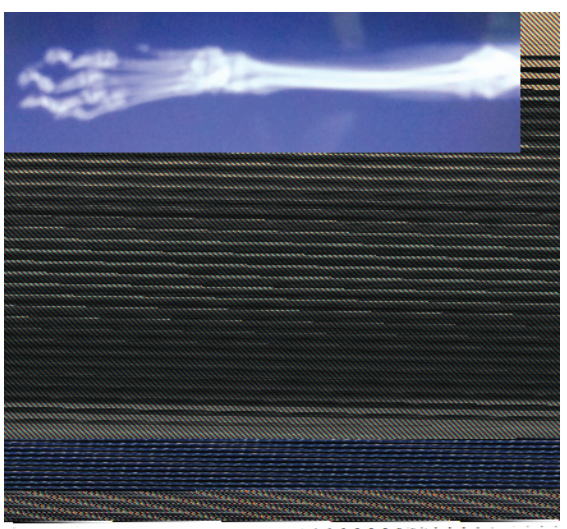

FIGURA 5. Proyección latero lateral de cadera. Elaboración propia.

\section{Miembros anteriores}

\section{Proyección latero medial (LM)}

- Ubicar al paciente en decúbito lateral, teniendo en cuenta el lado requerido.

- Ubicar los miembros sobre el chasis.

- Estirar un miembro caudalmente y el otro cranealmente.

- Tomar la radiografía.

\section{Proyección Antero posterior (AP)}

- Ubicar al paciente en decúbito esternal.

- Colocar los miembros anteriores sobre el chasis.

- Estirar los miembros cranealmente.

- Tomar la radiografía.

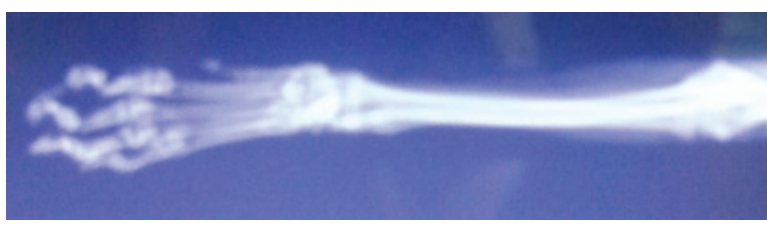

FIGURA 6. Proyección antero posterior de miembro anterior izquierdo. Elaboración propia. 


\section{Miembros posteriores}

\section{Proyección latero medial (LM)}

- Ubicar al paciente en decúbito lateral, teniendo en cuenta el lado requerido.

- Ubicar los miembros sobre el chasis.

- Estirar un miembro caudalmente y el otro cranealmente.

- Tomar la radiografía.

\section{Proyección Antero posterior (AP)}

- Ubicar al paciente en decúbito esternal.

- Colocar los miembros anteriores sobre el chasis.

- Estirar los miembros cranealmente.

- Tomar la radiografía.

\section{Neumocistografía}

La neumocistografía se indica para evaluar morfológicamente la vejiga (posición, integridad, distensión, espesor de pared, ruptura), presencia de cálculos y si la calidad del estudio lo permite se puede visualizar el reflujo uretral y patologías prostáticas (Thrall, 2003).

\section{Preparación del paciente}

- Colocar sonda en vejiga y vaciarla.

- $\quad$ Si es necesario anestesiar al paciente.

- Si hay presencia de coágulos de sangre, se requiere lavar con solución fisiológica y extraerlos.

\section{Técnica}

- Se requieren dos tomas radiográficas: en proyección latero lateral y en ventrodorsal.
- Se ubica el paciente en decúbito lateral y en decúbito dorsal.

- Se requiere una jeringa con aire (aproximadamente $20 \mathrm{cc}$ ).

- Se ubica el haz de rayos x a nivel de la vejiga.

- Estirar las extremidades anteriores cranealmente y las posteriores caudalmente.

- Al ingresar el aire por la sonda, se debe tomar la radiografía.

\section{Gastrografía}

Está indicada para evaluar los pacientes con signos clínicos de enfermedad gástrica, para evaluación de desplazamiento gástrico o enfermedad obstructiva pilórica.

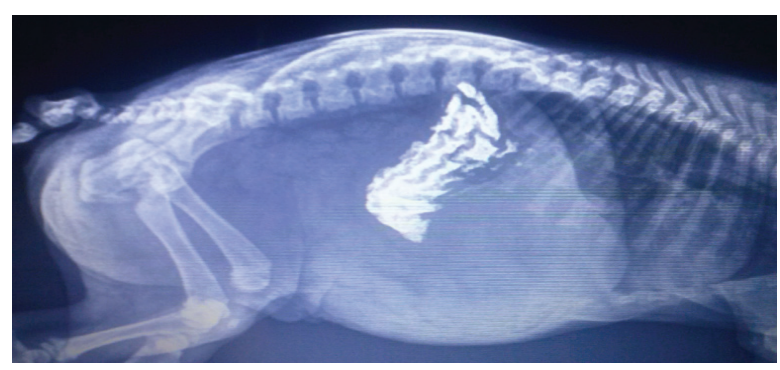

FIGURA ?. Paciente con medio de contraste. Elaboración propia.

\section{Preparación del paciente}

- Administrar sulfato de bario al 30\% p/v por vía oral o sonda gástrica, a una dosis de $1-2 \mathrm{cc} / \mathrm{Kg}$.

\section{Técnica}

- Se requieren dos tomas radiográficas: en proyección latero lateral y en ventrodorsal.

- Se ubica el paciente en decúbito lateral y en decúbito dorsal.

- Estirar las extremidades anteriores cranealmente y las posteriores caudalmente. 
- Se ubica el haz de rayos x dependiendo la zona de recorrido del sulfato de bario.

- La primera toma se realiza al momento de administrar el sulfato de bario, luego se realizan tomas de 20 - 30 minutos de diferencia.

- La cantidad de tomas depende del recorrido del sulfato de bario y de la opinión del radiólogo para dar el diagnóstico.

\section{EQUIPO DE ECOGRAFÍA}

La ecografía es una técnica diagnóstica en la que se emplean ondas de alta frecuencia para observar imágenes de tejidos blandos u órganos, en la pantalla del ecógrafo y es de gran utilidad para el diagnóstico de enfermedades, tumores y problemas que no se pueden observar a simple vista o por medio de otras imágenes como la radiografía y no implica lesiones para el paciente o para el profesional.

En Veterinaria, la ecografía es indispensable y altamente usada por los profesionales veterinarios, solo implica el uso de un transductor que se coloca en el cuerpo del paciente, siendo un método seguro y no doloroso. Las imágenes son captadas en tiempo real, por lo cual, pueden mostrar la estructura y el movimiento de los órganos. Es empleada para diagnosticar diversas patologías abdominales, reproductivas, preñez y con la ecocardiografía se diagnostican patologías cardiacas mediante mediciones de la pared, el funcionamiento valvular, entre otros.

\section{Principios físicos}

La ecografía es la técnica que emplea el ultrasonido para definir los órganos. Cada uno de los tejidos proporciona propiedades acústicas que generan las imágenes que en el ecógrafo representan al órgano observado.

\section{Principios físicos básicos}

El sonido es la forma de energía mecánica que se propaga a través de la materia en forma de ondas, la cuales presentan características básicas:

- Ciclo: es el fragmento de la onda, comprendido entre dos puntos iguales de su trazado.

- Longitud de onda (L): es la distancia en la que la onda realiza un ciclo completo.

- Frecuencia (f): es el número de ciclos por unidad de tiempo (segundo). Se expresa en hertzios.

- Amplitud (A): es la altura máxima que alcanza una onda. Está relacionada con la intensidad del sonido y se mide en decibe$\operatorname{lios}(\mathrm{dB})$.

La longitud de onda y la frecuencia se relacionan con la velocidad del sonido por la siguiente formula: $\mathrm{L}=\mathrm{v} / \mathrm{f}$. Por tanto, para una misma velocidad del sonido, la longitud de onda es inversamente proporcional a la frecuencia (figura 8).

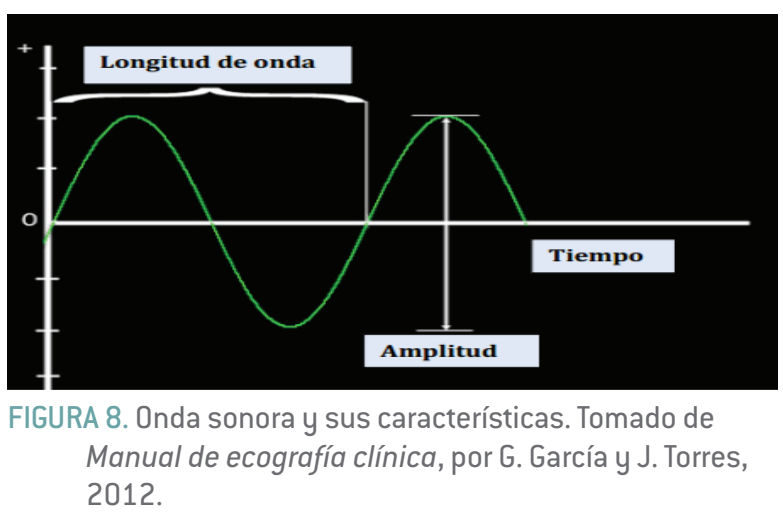

Formación de la imagen ecográfica

La utilización de los ultrasonidos en la medicina se basa en el descubrimiento del efecto piezoeléctrico (García y Torres, 2012). Mediante este efecto, al someter un cristal a una corriente eléctrica, la diferencia de potencial que se obtiene hace que vibre el interior del 
cristal y, por lo tanto, se genere un haz de ultrasonidos.

Un ecógrafo está conformado por un transductor o sonda ecográfica, una unidad de procesamiento y por un monitor. Los transductores contienen cristales que, al ser sometidos a la electricidad, generan los haces de ultrasonido; estos también son capaces de captar los ultrasonidos que los tejidos generan y los remiten a la unidad de procesamiento para que se genere la imagen y pueda ser visualizada en el monitor.

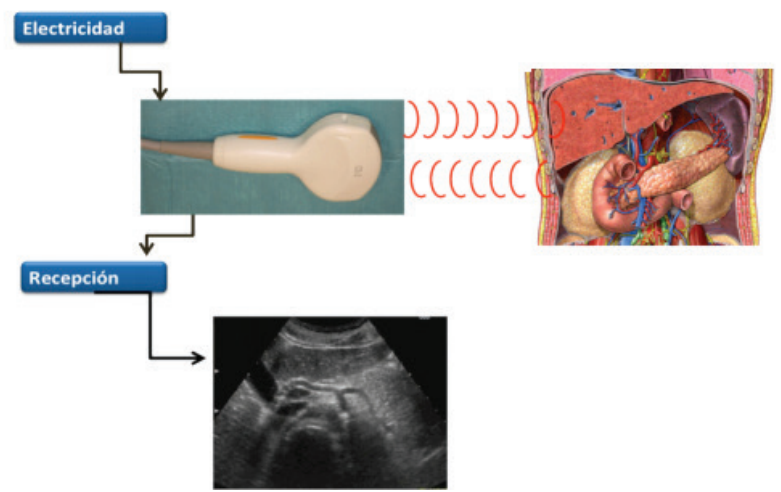

FIGURA 9. Elementos o constituyentes del ecógrafo. Tomado de Manual de ecografía clínica, por G. García y J. Torres, 2012.

La calidad o la resolución de la imagen depende de la capacidad de distinguir la morfología normal o alterada en los tejidos (resolución de contraste) y de la capacidad de diferenciar objetos próximos (resolución axial y lateral; Szabo, 2004).

- Resolución axial: permite distinguir dos objetos como separados cuando están situados uno encima del otro y depende de la frecuencia del transductor. A mayor frecuencia, mayor resolución axial y viceversa.

- Resolución lateral: esta resolución permite distinguir dos objetos separados, cuando están uno al lado del otro. Depende del tamaño del transductor y se puede modificar ajustando el ancho del pulso en la zona focal.

\section{Ecogenicidad de los tejidos}

Los ecos de los ultrasonidos que son captados por el transductor se representan como un punto o pixel en el monitor, mediante una escala de colores grises de diferente brillo, el cual depende de la amplitud del eco reflejado (figura 10). Los haces de ultrasonido se transmiten bien a través de sangre o líquidos y apenas son reflejados (figura 11), a esto se le define ecográficamente como anecoico o hipoecoico. Los huesos y el aire reflejan con gran intensidad los ultrasonidos, se determina como hiperecogénico.
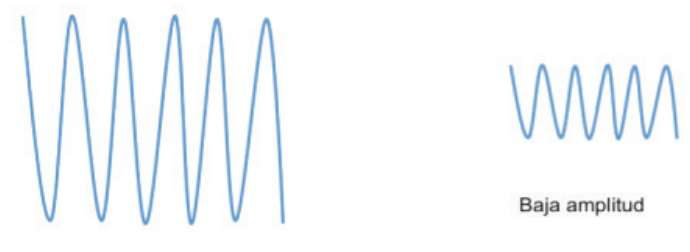

Baja amplitud

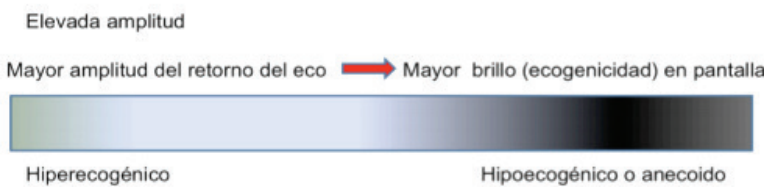

FIGURA 10. Relación entre amplitud del eco reflejado y el brillo en escala de grises. Tomado de Manual de ecografía clínica, por G. García y J. Torres, 2012.

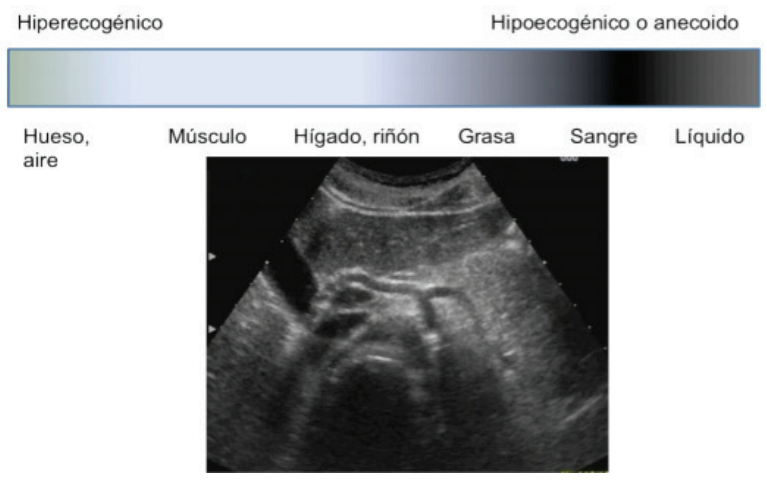

FIGURA 11. Ecogenicidad de los diferentes constituyentes de los tejidos. Tomado de Manual de ecografía clínica, por G. García y J. Torres, 2012.

\section{Artefactos}

Con frecuencia, cuando se forma una imagen ecográfica, puede generarse artefactos, que forman parte de la imagen sin corresponder a la anatomía real. Es de gran importancia 
conocer los diferentes artefactos que se presentan para evitar errores en la interpretación de las imágenes. Se destacan:

\section{Sombra acústica}

Se presenta cuando el haz de ultrasonidos choca con una superficie reflectante que rebota todos los eco y se observa una imagen hiperecoica, pero detrás de la misma, se produce una sombra anecoica. Por ejemplo: hueso, metal, calcio.

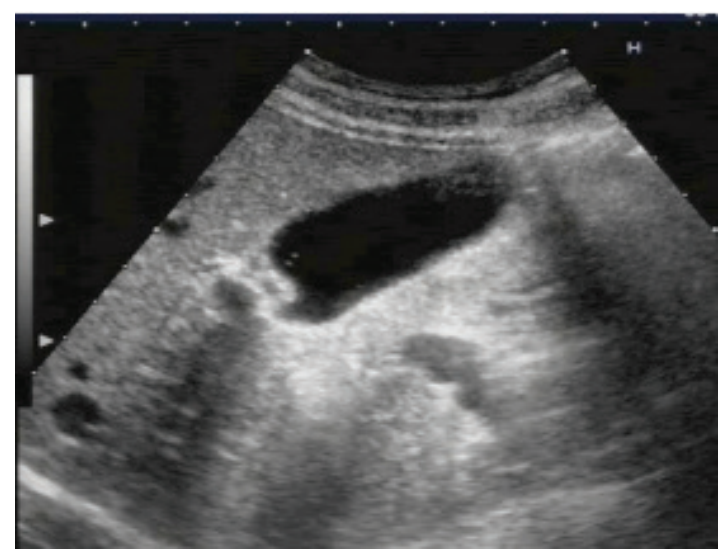

FIGURA 12. Vesícula biliar con un cálculo en su interior. Tomado de Manual de ecografía clínica, por G. García y J. Torres, 2012.

\section{Refuerzo posterior}

Es un fenómeno contrario a la sombra acústica. Se presenta cuando el haz de ultrasonido atraviesa tejidos con poca atenuación como los líquidos y dificultan su paso, se produce un falso aumento de la ecogenicidad por detrás de esas estructuras.

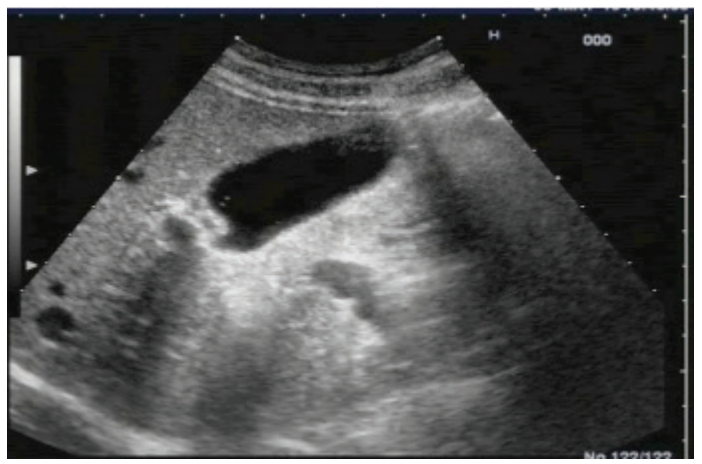

FIGURA 13. Imagen de la vesícula biliar con su refuerzo ecográfico posterior. Tomado de Manual de ecografía clínica, por G. García y J. Torres, 2012.

\section{Reverberación}

Es cuando el haz de ultrasonidos atraviesa una interfase que separa dos medios de diferente impedancia acústica. Se observan muy ecogénicas, por ejemplo, el gas.

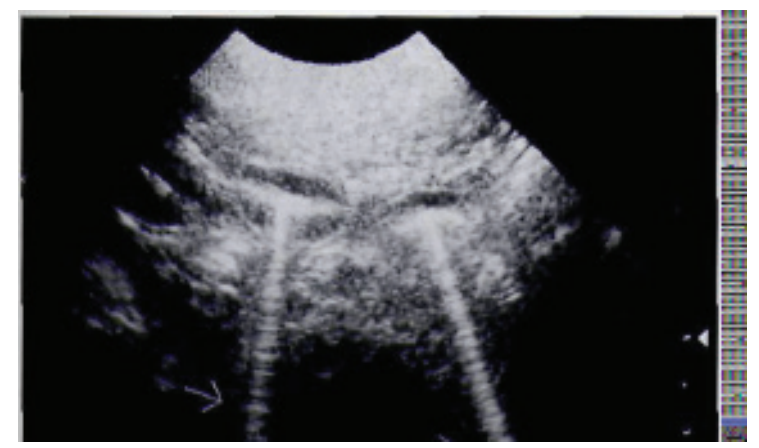

FIGURA 14. Artefacto de reverberación interna producido por un asa intestinal llena de gas situada superficialmente. Tomado de Diagnóstico ecográfico en pequeños animales, por T. Nyland, J. Mattoon, E. Herrcesell y E. Wisner, 2010.

\section{Cola de cometa}

Se presenta cuando el haz de ultrasonidos choca con una interfase estrecha y muy ecogenica. Por ejemplo, pleura o peritoneo.

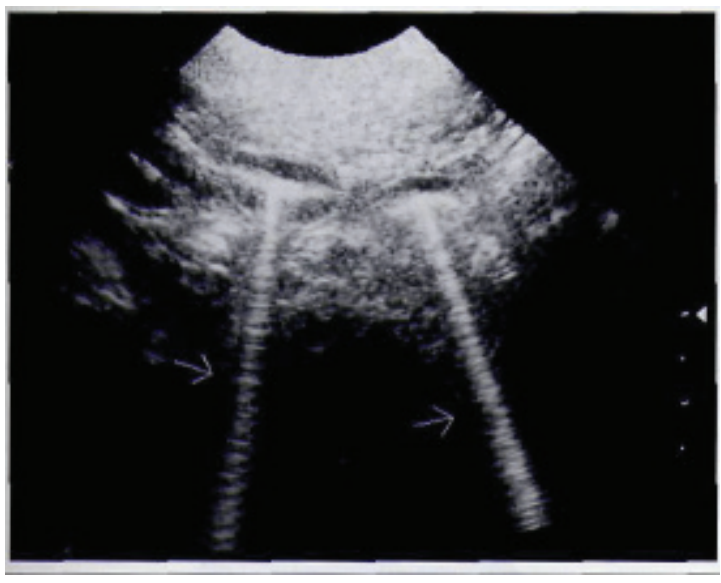

FIGURA 15. Artefacto en cola de cometa (flechas). Tomado de Diagnóstico ecográfico en pequeños animales, por T. Nyland, J. Mattoon, E. Herrcesell y E. Wisner, 2010.

\section{Imagen en espejo}

Se presenta cuando el haz de ultrasonidos atraviesa una superficie altamente reflectante, como el diafragma o el pericardio, e incide sobre ella con determinada angulación. Parte de los ultrasonidos se reflejan 
hacia delante y atrás produciendo imágenes en espejo.

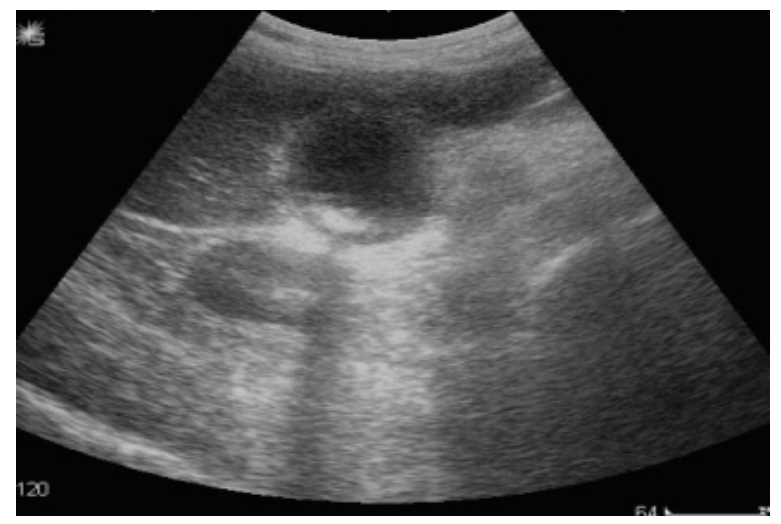

FIGURA 16. Imagen en espejo de la vesícula biliar. Tomado de Manual de ecografía clínica, por G. García y J. Torres, 2012.

\section{Anisotropía}

No es un artefacto como tal, se debe a la propiedad que tienen algunos tejidos para variar su ecogenicidad dependiendo del ángulo de incidencia del ultrasonido. Por ejemplo, el tendón.

\section{El ecógrafo y sus componentes}

El ecógrafo se compone de elementos básicos que son: transductor, procesador y monitor. Para la realización de las ecografías se requiere de gel para ecografía que permite una mejor visualización de los órganos en el monitor.

\section{Comandos}

Son imprescindibles para el manejo de los ecógrafos. Los comandos son:

- Ganancia (gain): este comando modifica la ganancia global y modifica la intensidad de las ondas de ultrasonidos emitidas/ recibidas.

- Profundidad (depth): este comando modifica la penetración que se observa en la pantalla.
- Pausa (freeze): comando que congela la imagen que se está observando en la pantalla.

- Guardar (save): comando que almacena las imágenes o los videos seleccionados.

- Medición (measurement): comando utilizado para realizar mediciones cuando la imagen está congelada.

- Foco (focus): este comando se emplea para mejorar la resolución de la imagen a un determinado nivel.

- Imprimir (print): permite imprimir las imágenes si el equipo dispone de una impresora térmica.

\section{Transductores o sondas}

Los transductores son la parte esencial que componen los ecógrafos. Tienen en su interior cristales piezoeléctricos, que transforman la energía eléctrica en energía mecánica, y es el receptor de los haces de ultrasonidos, los cuales transforma en energía eléctrica para generar las imágenes.

Existe gran variedad de transductores, dependiendo de la forma, el tamaño y la frecuencia de los haces de ultrasonido que emite. Las sondas de mayor frecuencia proporcionan mayor definición pero menor profundidad y solo permiten observar estructuras superficiales y las sondas de menor frecuencia tienen menor definición pero mayor profundidad (Goddard, 2000).

- Sonda lineal: es de alta frecuencia por lo tanto es utilizada para observar estructuras superficiales.

- Sonda convex: es una sonda de baja frecuencia y se emplea generalmente para la exploración de las estructuras de la cavidad abdominal. 
- Sonda sectorial: es una sonda de baja frecuencia y es ideal para realizar ecocardiogramas.

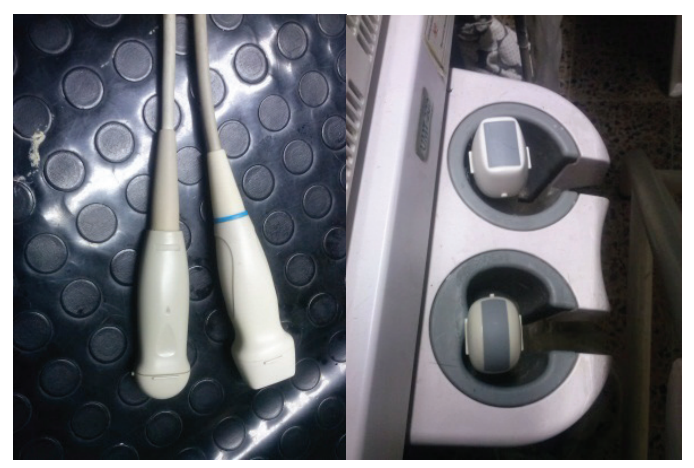

FIGURA 17. Transductores. Elaboración propia.

\section{Planos ecográficos}

Al realizar ecografías, para cada órgano se efectúan cortes definidos por un plano cuya orientación corresponde a la propagación de los ultrasonidos.

- Plano transversal: El transductor se coloca perpendicular a la columna vertebral del paciente. Son cortes oblicuos con inclinación craneal o caudal, derecha o izquierda.
- Plano mediano o paramediano: Son cortes longitudinales que pasan por un plano de simetría.

- Plano frontal: Atraviesa perpendicular al plano sagital y paralelos a la columna vertebral mediante abordaje lateral derecho o izquierdo.

Para orientarse, en ecografía, la derecha del animal está a la izquierda en la pantalla y la izquierda de animal a la derecha, la parte anterior a la izquierda y la posterior a la derecha de la pantalla, la cara ventral está a la izquierda y la dorsal a la derecha de la pantalla en cortes transversales efectuados mediante abordaje lateral (Díez, 1992).

\section{Modos en ecografía}

Teniendo en cuenta el efecto piezoeléctrico, los ecos reflejados en las diferentes interfaces reflectantes, chocan con los cristales de la sonda donde generan una corriente eléctrica que es analizada por la unidad de procesamiento y expresada en el monitor de distintas formas o modos. Como un vector (modo A), como un punto móvil (punto M) o como un punto de determinado nivel de gris (modo B) (Kealy, McAllister y Graham, 2010).

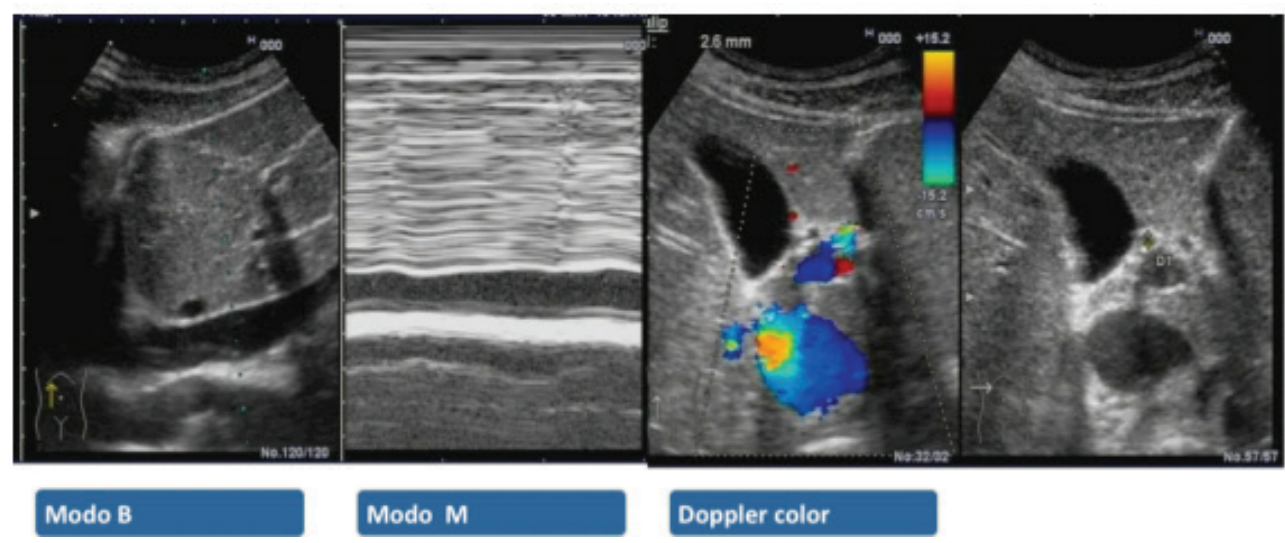

FIGURA 18. Diferentes modos ecográficos. Fu Tomado de Manual de ecografía clínica, por G. García y J. Torres, 2012.

- Modo B: en este modo se obtiene una imagen bidimensional en tiempo real. El ecógrafo convierte las diversas amplitudes de las ondas captadas en pixeles. (A mayor amplitud de onda, mayor brillo en escala de grises.) 
- Modo M: representa el movimiento de la interface reflectante, su utilidad es valorar situaciones clínicas en las que se requiere de movimiento.

- Modo D (Doppler): se basa en el cambio de frecuencia del sonido que se produce cuando una onda acústica choca con una interface en movimiento, es posible captar el movimiento del haz de ultrasonidos reflejado cuando se acercan o se alejan del transductor (Böhmeke y Schmidt, 2010). Este modo se utiliza para captar los flujos de sangre dentro de los vasos sanguíneos o en el corazón. Los movimientos se registran de dos formas:

- Doppler color: los movimientos toman color, por lo que el flujo que se aleja del transductor toma color azul y el flujo que se acerca toma color rojo. No sirve para diferenciar arterias de venas (Yuste y García-Fernandez, s. f.).

- Doppler pulsado: genera graficas en forma de onda, que son positivas o negativas dependiendo del flujo cuando se aleja o se acerca.

\section{Protocolo de realización de ecografías}

Para la realización de las ecografías, se debe tener en cuenta los siguientes pasos:

- Registrar al paciente en la base de datos al ingresar a la clínica.

- Se asignará un rotante, que tomará los datos, llenará la historia clínica y estará al cuidado del paciente.

- El paciente será revisado por un Médico Veterinario el cual determinará si es necesario realizar la ecografía.

- Se llenará la orden de exámenes de la clínica, en el cual se indicarán los datos del paciente.
- El rotante deberá preparar al paciente para la ecografía: rasurar la zona indicada por el médico veterinario (abdomen o zona precordial).

- Se llevará el paciente al área de imagenología diagnóstica, con la orden cancelada y se esperará el turno.

- Se ubicará al paciente sobre la mesa para ecografías y se ubicara en decúbito dorsal.

- El Médico Veterinario ingresará los datos del paciente al ecógrafo.

- Se aplica gel en la zona a examinar y se ubica el transductor.

- médico veterinario examina las imágenes y da el diagnóstico al propietario del paciente.

\section{EQUIPO DE ENDOSCOPIA}

La endoscopia es una técnica empleada para visualizar dentro de un órgano hueco. La palabra endoscopia deriva de la palabra griega endo que significa 'dentro' y del verbo griego skopia que significa 'observar'. Actualmente es una técnica altamente utilizada en la medicina para realizar hallazgos patológicos y toma de biopsias.

En veterinaria ha tenido gran acogida, especialmente en las patologías gastrointestinales, ya que se puede utilizar como medio de diagnóstico o como medio terapéutico. De igual forma, al poder visualizar los órganos y su contenido, es una herramienta de gran ayuda para la extracción de cuerpos extraños.

En la clínica veterinaria esta herramienta diagnóstica se emplea para pacientes con problemas gastrointestinales, que requieren observación más detallada de los órganos, mucosas, contenido y para la extracción de tejidos que deben ser analizados patológicamente. 


\section{Composición de un endoscopio}

Los endoscopios, se diferencian por su longitud, diámetro exterior, capacidad de angulación para mejorar los campos visuales, diámetro del canal operador y el visor en el extremo distal.

Consta de una fuente de luz y aire, una bomba de aspiración, un procesador de imágenes con controles de luz y color y un monitor.
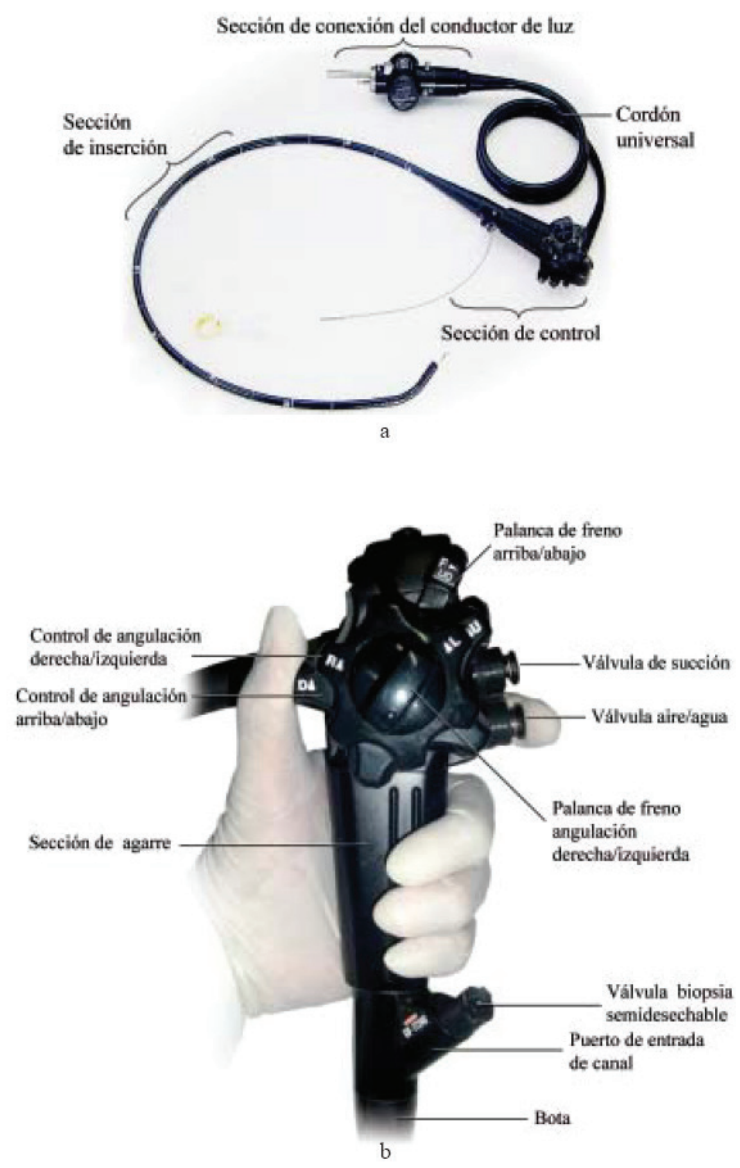

FIGURA 19. Partes de un endoscopio. A] secciones; B] sección de control. Tomado de Manual de endoscopia digestiva superior diagnóstica, por $\mathrm{H}$. HernándezGarcés, 2003.

Tipos de endoscopios

\section{Endoscopio flexible}

Es el endoscopio más común y utilizado. La imagen es transmitida digitalmente por el interior de la sonda flexible hasta el monitor
(Brearley, Cooper y Sullivan, 1991). La cabeza de la sonda es articulable y dirigible desde el exterior mediante una palanca de mando, que permite rotaciones de hasta $180^{\circ}$ en todas las direcciones.

\section{Limpieza y desinfección}

El procedimiento se esquematiza de la siguiente forma:

- Limpieza preliminar:

- Aspiración y purga de los canales: al finalizar el procedimiento de la endoscopia se debe realizar una limpieza de los canales de aire y agua, según las indicaciones de los fabricantes, para remover cualquier residuo que puedan contener.

- Lavado manual:

- Limpieza de los canales

- Control de la capacidad

- Limpieza preliminar

- Desinfección: los endoscopios clasificados como críticos deben esterilizarse empleando métodos que sean aprobados por los fabricantes. Los demás endoscopios requieren de una desinfección de alto nivel con esterilizantes químicos líquidos (Twedt, 2001).

- Secado: luego de desinfectar el equipo, se debe enjuagar y secarlo bien con un paño y con alcohol para facilitar el secado.

- Almacenamiento: Los endoscopios deben almacenarse en un área ventilada con el cabezal asegurado hacia arriba y la parte distal del tubo de inserción colgando hacia abajo (Tams y Rawlings, 2010).

\section{Protocolo de realización de endoscopias}

Para realizar endoscopias, se deben tener en cuenta los siguientes pasos: 
- Registrar al paciente en la base de datos al ingresar a la clínica.

- Se asignará un rotante, que tomará los datos, llenará la historia clínica y estará al cuidado del paciente.

- El paciente será revisado por un Médico Veterinario el cual determinará si es necesario realizar la endoscopia.

- Se llenará la orden de exámenes de la clínica, en el cual se indicarán los datos del paciente.

- El rotante deberá preparar al paciente para la endoscopia y pedir los insumos necesarios para la realización de la misma.

- Se llevará el paciente al área de imagenología diagnóstica, con la orden cancelada y se esperará el turno.

- Se ubicará al paciente sobre la mesa y se procederá a sedarlo y colocarle el tubo endotraqueal (dependiendo de las especificaciones del paciente se escogerá el tamaño del tubo)

- El rotante deberá prestar cuidado a los signos vitales del paciente

- El Médico Veterinario introducirá la fibra óptica y comenzará el recorrido por el tracto digestivo del paciente en busca de alteraciones.

- El médico veterinario examina en la pantalla del endoscopio cada una de las zonas que va recorriendo y determinará la patología del paciente

\section{OBjetivos}

\section{Objetivo general}

- Lograr que el estudiante tenga la competencia e identifique la importancia del uso de todos y cada uno de los equipos requeridos por el área de imagenología como herramienta complementaria en el manejo clínico y diagnóstico en el campo de la Medicina Veterinaria y Zootecnia.

\section{Objetivos específicos}

- Capacitar tanto de forma teórica como práctica al estudiante, en el uso y manejo de los equipos de radiología, endoscopia y ecografía, pertenecientes al área de imagenología diagnóstica.

- Comprender la importancia de las normas de bioseguridad y su aplicabilidad, establecidas para cada uno de los equipos pertenecientes al área de imagenología diagnóstica.

- Correlacionar clínicamente los hallazgos de las imágenes obtenidas de los diferentes equipos, con la presentación clínica y sintomática de todos y cada uno de los pacientes que necesiten del uso del área como medio complementario de diagnostico

\section{MATERIALES}

La metodología para soportar el correcto entendimiento de la siguiente guía será basado en el desarrollo de un taller práctico que constara de los siguientes puntos:

1. Para la evaluación radiógica, buscar un paciente sano o que clínicamente este cursando con algún tipo de patología que sea detectable a nivel radiológico. Después de este paso, deberán determinar, según lo que quieran explorar radiológicamente, cuál va a ser el manejo más adecuado para el animal, qué posición radiológica necesitará la mascota según la estructura que se quiera visualizar, qué vistas radiológicas se necesitan y cuántas serían realmente importantes para emitir un correcto diagnóstico y si se necesita o no alguna técnica especial para la toma de 
la(s) placa(s) radiográfica(s). Cabe resaltar que se tendrá en cuenta el uso adecuado del equipo, su correcta calibración y el manejo de los implementos de radio protección necesarios para la toma y el uso del equipo.

2. Para la evaluación ecográfica, buscar un paciente sano o que clínicamente esté cursado con algún tipo de patología; en este caso, el estudiante se encargará de hacer la preparación completa del paciente destinado para valoración ecográfica, realizará una leve explicación de por qué está indicado el proceso ecográfico e identificará cada una de las estructuras anatómicas que podamos observar según su posición, valorará ecogenicidades de estas mismas estructuras efectuando la correcta explicación del porqué de cada una de ellas, identificará y nombrará de manera correcta los posibles artefactos ecográficos que podamos encontrar en una valoración de este tipo y por qué se pueden generar los mismos.

3. Para la valoración endoscópica, siendo esta técnica de diagnóstico un poco más compleja porque necesita condiciones especiales para la consecución de un paciente, se tomará la alternativa de crear un simulador, el cual constará de un sistema digestivo obtenido éticamente para el desarrollo de la práctica, el cual será sumergido en gelatina para que nos permita un uso y exploración adecuada por medio del equipo de endoscopia. Aquí el estudiante mediante el uso del equipo debe argumentar para que sirve cada uno de los componentes del equipo de endoscopia, cuándo está indicado su uso y cuáles son los beneficios diagnósticos que este nos puede generar; anexo a esto, debe conocer de antemano la estructura que va a explorar y las posibles alteraciones que se puedan presentar en cada una de ellas 


\section{REFERENCIAS}

Böhmeke, T. y Schmidt, A. (2010). Ecocardiografía guía de consulta rápida. Bogotá: Editorial Médica Panamericana. Recuperado de: http://books.google.com.co/books?id=ooOBtDZZmjcC\&printsec=frontcover\&hl=es\#v=0nepage\&q\&f=false

Brearley, M. J., Cooper, J. E. y Sullivan, M. (1991). Atlas de endoscopia en pequeños animales. Barcelona: Grass ediciones.

Díez, N. (1992). Principios básicos de la ecografía. Clínica Veterinaria de Pequeños Animales, 12. Retrieved from http://ddd.uab.cat/pub/clivetpeqani/11307064v12n3/11307064v12n3p138.pdf

Flores-Alés, A. (2007). El equipo de endoscopia. Ateuves, 9, 36-39. Retrieved from http://www.veterinaria.org/ ajfa/elequipodeendoscopia.pdf

García, G. y Torres, J. (2012). Manual de ecografía clínica. Retrieved from http://www.tauli.cat/tauli/cat/Lacorporacio/elscentres/HS/webs/Urgencies/6_Info_professionals/Pautes_actuacio/radiologia/Manual_Ecografia_SEMI_PAUTAS.pdf

Goddard, P. J. (2000). Ecografía veterinaria. Editorial Acribia S.A.

Gutierrez, J. E. (2004). Radiología e imagenes diagnósticas. Corporación para investigaciones biológicas.

Han, C. M. y Hurd, C. D. (2000). Diagnóstico practico por imagen para técnicos veterinarios. Editorial Acribia S.A.

Han, C. M., Hurd, C. D. y Kurklis, L. (1997). Diagnóstico por imagen, guía práctica de radiología y ecografía. Editorial Harcourt Brace.

Hernandez-Garcés, H. (2003). Manual de endoscopia digestiva superior diagnóstica. Retrieved from http://gsdl.bvs. sld.cu/cgi-bin/library?e=d-00000-00---off-0imaginol--00-0----0-10-0---0---0direct-10---4------0-11--11-ky50---20-about---00-0-1-00-0-0-11-1-0gbk-00\&a=d\&cl=CL3.5\&d=HASH6c6a967fa4d83a56e538e3.8.1

Joel Edwards, N. (1993). ECG Manual for the veterinary technician (First edit.). Saunders.

Kealy, J. K., McAllister, H., y Graham, J. P. (2010). Diagnostic radiology and ultrasonography of the dog and cat (fifth edit.). Elsevier Health Sciences. Retrieved from http://books.google.com.co/books?id=IJ18JUlz9mMC\&printsec $=$ frontcover\&dq=radiologic $+i n+$ the + dog\&hl=es $-419 \& s a=X \& e i=2 U X R U 67 C P M v j s A S x o-$ 4 HoDA\&ved=0CBwQ6AEwAA\#v=onepage \& $\mathrm{q}=$ radiologic in the dog\&f=false

Liste, F. (2010). Atlas veterinario de diagnóstico por imagen. Zaragoza. Retrieved from file:///C:/Users/Jennifer Gualdron/Downloads/atlasvetdiagnostico.pdf

Lois, A. A. (2010). Apuntes de radiologia practica de pequeños animales N. ${ }^{\circ}$. REDVET, 11. Retrieved from http:// www.veterinaria.org/revistas/redvet/n040410/041014.pdf

Loriot, N., Martinot, S. y Franck, M. (1997). Ecografía abdominal del perro y el gato. Retrieved from http://books. google.com.co/books?id=v4ceQULE-lic\&printsec=frontcover\&hl=es\#v=onepage\& $q \& f=$ false

Meder, A. (2010). Utilidad de la electrocardiografía en la clínica veterinaria de animales de compañía. Ciencia Veterinaria, 12, 39-43. Retrieved from http://www.biblioteca.unlpam.edu.ar/pubpdf/revet/n12a07meder. pdf

Mendoza, J. (s. f.). Conceptos básicos de radiología veterinaria. Recuperado de: www.mvzunipaz.edu.co\%2Fdocumentos\%2Fbiblioteca\%2Flibros\%2Fimagenologia\%2FConceptos\%2520b\%25E1sicos\%2520de\%2520radiolog\%25EDa\%2520veterinaria\%2520Mendoza.pdf

Montoya, J. A. y Ynaraja, E. (2007). Manual práctico de electrocardiografía en pequeños animales. Recuperado de: http://books.google.com.co/books?id=e-AocL2OinOC\&printsec=frontcover\&dq=electrocardiografia+veterinaria\&hl=es\&sa=X\&ei=cxhGU-yVD46X0gGZxICYBQ\&ved=0CCwQ6AEwAA\#v=onepage\&q=electrocardiografia veterinaria $\& \mathrm{f}=$ false

Moreno-Gómez, R., y García-Fernandez, M. (1999). Electrocardiografía básica: cómo leer electrocardiogramas. McGraw-Hill Interamericana de España S.L.

Nyland, T., Mattoon, J., Herrcesell, E. y Wisner, E. (2010). Diagnóstico ecográfico en pequeños animales. 
Preciado, M. y Luna, V. (2010). Medidas básicas de protección radiologica. Cancerología, 1, 25-30. Recuperado de: http://www.incan.org.mx/revistaincan/elementos/documentosPortada/1294860259.pdf

Roldán-Arjona, J. M. (s. f.). Efectos de la radiación sobre el organismo. Retrieved from http://www.apccc.es/arch_ apccc/tertulias/Radiacion/radiacion.pdf

Santamarina, G., Torío, R. y Suárez, M. L. (s. f.). Electrocardiografia. Consulta de Difusión Veterinaria. Recuperado de: http://www.mvzunipaz.edu.co/documentos/biblioteca/libros/imagenologia/electrocardiografia_veterinaria.pdf

Szabo, T. (2004). Diagnostic ultrasound imaging: inside out. Elsevier academic press. Recuperado de: http://books. google.com.co/books?id=-Fd1Pkeh2T0C\&printsec=frontcover\&hl=es\#v=onepage\&q\&f=false

Tams, T. R. y Rawlings, C. A. (2010). Small animal endoscopy (3rd ed.). Elsevier Health Sciences.

Thrall, D. E. (2003). Manual de diagnóstico radiológico veterinario. Elseiver España.

Tilley, L. P. y Burtnick, N. L. (1999). ECG Electrocardiography for the small animal practitioner. Recuperado de: http:// books.google.com.co/books?id=sOsb_mvofhcC\&printsec=frontcover\&hl=es\#v=onepage\&q\&f=false

Twedt, D. C. (2001). Gastrointestinal endoscopy in dogs and cats. Ralston Purina.

Unzeta, R. S. A. (2009). Manual de posiciones y proyecciones en el perro. Recuperado de: http://www.edicioneselprofesional.com.co/pdf/658.pdf

Vaneiro, G., Vidal, J. L., Fernández, P., Viana, P. y Banina, D. (2006). Artefactos y seudoartefactos en el electrocardiograma. Revista Uruguaya de Cardiología, 21. Recuperado de: http://www.suc.org.uy/revista/v21n3/pdf/ rcv21n3_10.pdf

Ynaraja, E., Montoya, J.A. y Bernal,J. (2004). Manual de electrocardiografía en la clínica del perro. Boehringer-Ingelheim. Yuste, P. y García Fernandez, M. (s. f.). Atlas de ecocardiografía bidimensional y doppler. Bogotá: Ediciones Norma, S.A. Recuperado de: http://books.google.com.co/books?id=lVH6Onah3JoC\&printsec=frontcover\&hl=es\#v=onepage \&q\&f=false 


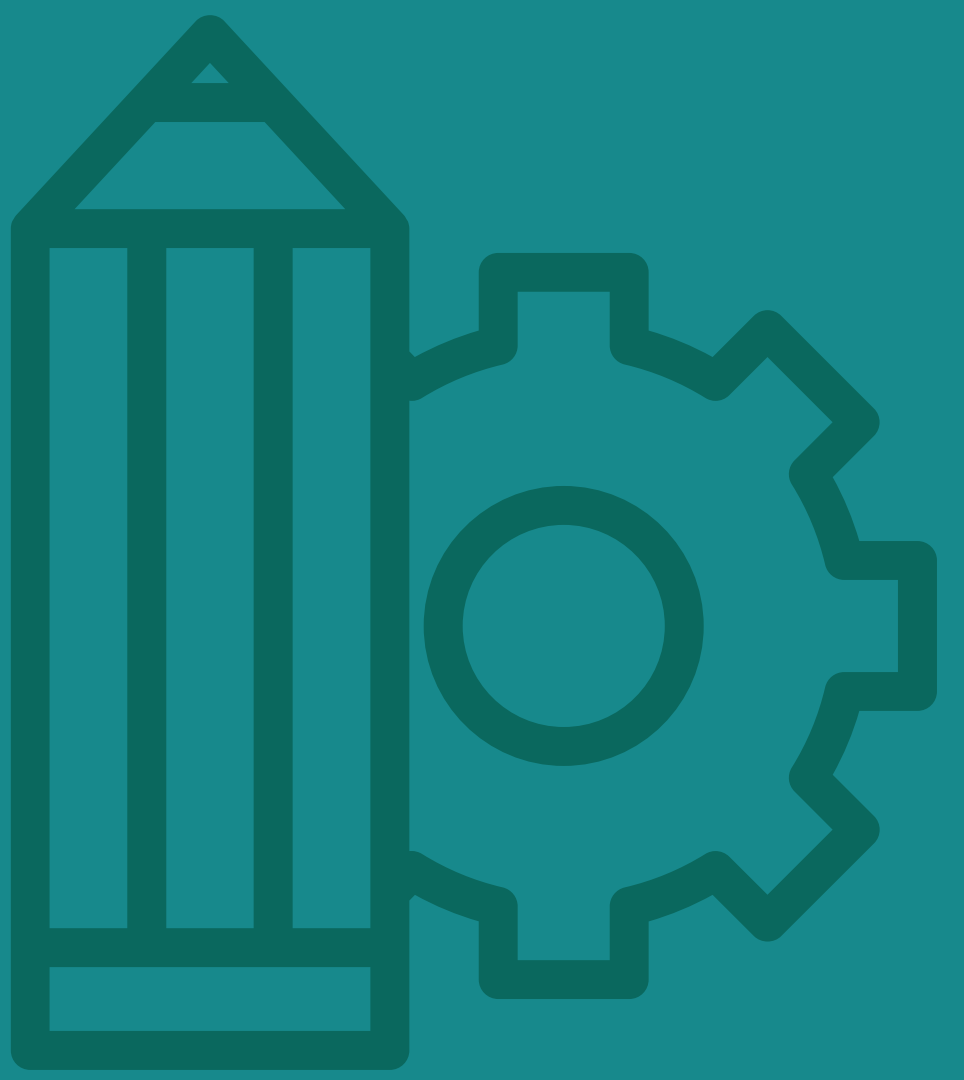

